\title{
O Cotidiano da Gestão Escolar: o método de caso na sistematização de problemas
}

Fabiana Martins Coelho'

'Centro de Políticas Públicas e Avaliação da Educação da Universidade Federal de Juiz de Fora (CAEd - UFJF), Juiz de Fora/MG - Brasil

RESUMO - O Cotidiano da Gestão Escolar: o método de caso na sistematização de problemas. Este artigo é resultado de um trabalho de pesquisa, intitulado Olhares Cotidianos sobre a Gestão Escolar, realizado pelo CAEd -UFJF em 2011. A fim de apreender as percepções de professores, coordenadores pedagógicos e diretores acerca da gestão escolar da qual fazem parte, foram realizados 17 grupos focais em 6 escolas públicas do município de Juiz de Fora. A metodologia proposta levou em conta dois processos importantes: sistematização de problemas e encaminhamento de soluções. Para isso, foram elaborados 17 cases inspirados em 5 categorias de problemas: relação da escola com a família, indisciplina do aluno, desamparo pedagógico, descontinuidades da prática docente e imprecisão no gerenciamento escolar.

Palavras-chave: Gestão Escolar. Cases. Resolução de Problemas.

ABSTRACT - The Daily Life of School Management: the case method in the systematization of problems. This article is the result of a research entitled Everyday Perspectives on School Management, conducted by CAEd-UFJF in 2011. In order to capture the perceptions of teachers, pedagogical coordinators and principals about the school management in which they belong, 17 focus groups were created in 6 public schools in the city of Juiz de Fora. The proposed methodology took into account two important processes: systemization of problems and solutions proposals. For this, 17 cases inspired by 5 categories of problems were developed: relationship between school and family, student indiscipline, pedagogical abandonment, discontinuity of teaching practices and inaccuracy in school management.

Keywords: School Management. Cases. Problem Solving.

Educação \& Realidade, Porto Alegre, v. 40, n. 4, p. 1261-1276, out./dez. 2015.1261 http://dx.doi.org/10.1590/2175-623647617 


\section{Introdução}

O trabalho que se segue apresenta os principais resultados obtidos na pesquisa intitulada Olhares Cotidianos sobre a Gestão Escolar (OCGE) realizada pelo Grupo 3 da Unidade de Pesquisa do Centro de Políticas Públicas e Avaliação da Educação (CAEd/UFJF). O projeto contou com 17 grupos focais constituídos por professores e gestores de seis escolas municipais da cidade de Juiz de Fora/MG, a fim de apreender as percepções acerca dos principais eventos e problemáticas do contexto escolar no qual esses profissionais estão envolvidos. Em cada uma das seis escolas, foram previstos três grupos focais temáticos: 1) Gestão e Letramento (professores e coordenadores pedagógicos), 2) Gestão e Matemática (professores e coordenadores pedagógicos) e 3) Gestão e Liderança Escolar (professores, coordenadores pedagógicos e gestores). Foi realizado, também, um quarto grupo focal, exclusivamente com as diretoras das escolas participantes.

Nos grupos temáticos, os debates contemplaram problemáticas relacionadas à gestão escolar de modo geral. Os roteiros que conduziram as discussões tinham o propósito de capturar as percepções dos gestores, professores e coordenadores pedagógicos em relação ao tipo de gestão da qual faziam parte. $\mathrm{O}$ registro desses encontros inspirou a redação de vários cases $^{1}$, que regressaram às escolas na etapa final da pesquisa. Nessa etapa - denominada devolutiva - os cases foram distribuídos em seis cadernos, um para cada escola. Em síntese, os problemas levantados nos grupos focais fomentaram a elaboração dos cases, que se constituíram em ferramenta de debate, troca de experiências e, sobretudo, proposição de soluções. Ou seja, os mesmos personagens que apontaram as dificuldades encontradas nas escolas deveriam, eles próprios, imaginar uma saída. Nesse sentido, os cases tornam-se bastante adequados, já que apontam tendências de práticas escolares e, o mais importante, abrem caminhos para a resolução de problemas cotidianos enfrentados por gestores, professores e funcionários.

O resultado dos debates sobre interesses comuns, a partir de diferentes contextos (escolas), quando sistematizados e organizados em narrativas, oferecem um poderoso instrumento reflexivo voltado para ações produtivas no interior das escolas. De modo concreto, esses profissionais foram ouvidos e tiveram a oportunidade de dialogar com os seus pares por, aproximadamente, duas horas em cada etapa, levantando problemas da prática, compartilhando ideias e soluções, além de oferecer um diagnóstico do processo de gestão em suas escolas.

Para efeitos de organização deste artigo, os resultados da pesquisa serão apresentados em três etapas. A primeira seção trata do hiato existente entre a teoria e a prática que se reflete no cotidiano dos professores. A segunda revela os principais problemas escolares identificados nos grupos e o modo como os participantes reagiram ao encaminhamento de resoluções desses mesmos problemas. A terceira e última etapa apresenta as considerações finais.

1262 Educação \& Realidade, Porto Alegre, v. 40, n. 4, p. 1261-1276, out./dez. 2015. 


\section{A Conciliação da Teoria com a Prática}

A relação existente entre a teoria e a prática carrega uma dicotomia quase impossível de ser superada, é o que costuma afirmar grande parte dos envolvidos no processo educativo. A máxima de que na teoria tudo é perfeito, ao contrário da prática parece ter sido cristalizada nas vozes docentes, sobretudo. Essa já desgastada expressão merecia um novo olhar a fim de orientar novas possibilidades de intervenção no contexto escolar. Para isso, era preciso avançar na proposição de metodologias inovadoras na maneira de se pesquisar. Por esse motivo, a alternativa proposta nesta pesquisa conjugou a metodologia de Grupo Focal com a de Cases.

As duas metodologias atuaram de modo complementar: os grupos foram eficazes tanto na etapa inicial, na qual foram levantados os problemas (insumo para a elaboração dos cases), como na etapa devolutiva (análise, resolução de problemas e tomada de decisão). Levando em conta que o ambiente de grupo tende a minimizar as opiniões falsas ou extremadas, proporcionando o equilíbrio e a fidedignidade dos dados, essa técnica se mostrou bastante produtiva no registro de percepções coletivas. Além disso, facilitou sobremaneira a execução da pesquisa, tanto em termos logísticos quanto financeiros.

O processo de formação dos grupos já oferecia dados curiosos. Nesse momento, foi possível identificar resistências, interesses e conflitos entre os profissionais das escolas participantes. Compor os grupos não foi tão simples como se supunha e os gestores optaram por marcar os encontros nos dias em que aconteciam as reuniões pedagógicas. $\mathrm{O}$ interesse pela pesquisa foi crescente e quando se deram conta de que o resultado final só se concretizaria mediante a participação efetiva deles, o respeito a essa nova configuração metodológica foi se tornando cada vez mais evidente. A descrença em relação ao papel de pesquisadores no interior da escola era unânime em todos os encontros. Muitos admitiam precisar de ajuda, orientação e boas ideias, mas se ressentiam ao constatar que nunca ou quase nunca recebiam retorno das infindáveis investidas acadêmicas nas escolas em que trabalham.

As dissonâncias entre teoria/prática e universidade/escola revelavam o descompasso existente entre as teorias acadêmicas e as condições objetivas de trabalho do professor. Os grupos temáticos, em sua totalidade, identificavam um distanciamento expressivo entre a linguagem da academia, as metodologias de ensino, as alternativas propostas e a vivência profissional de docentes e gestores. De fato, essa problemática aparecia com frequência, especialmente quando os temas discutidos estavam relacionados às metodologias de ensino. Nos depoimentos dos professores, a relação entre a teoria e a prática assume contornos diferenciados, ainda que expressem a mesma lógica: a lógica do distanciamento.

Educação \& Realidade, Porto Alegre, v. 40, n. 4, p. 1261-1276, out./dez. 2015. 
Segundo Catarina ${ }^{2}$, professora de Língua Portuguesa, o problema são os modismos que nos fazem assumir uma teoria parcialmente, já que como professoras não estamos estudando aquilo a fundo. O que a gente absorve é pela mídia ou por um texto que se lê. Para Lany, que atua como professora do $1^{\circ}$ ao $5^{\circ}$ ano do Ensino Fundamental é preciso urgência para lidar com as dificuldades de aprendizagem dos alunos: precisamos de sugestões práticas, coisas concretas. Nada de teoria.

De modo geral, essa foi uma questão muito recorrente nos grupos, com algumas variações importantes entre o grupo de Letramento e o de Matemática. No primeiro, o background do aluno era fortemente evocado como peça-chave de tudo o que envolve a prática docente. Por exemplo, algumas teorias do letramento pressupõem a exploração do contexto do aluno para que o aprendizado ocorra de modo mais eficiente. Nesse sentido, múltiplas linguagens estão em jogo: da universidade, da escola, do aluno, da família, da rua, da TV, dentre outras. Todas elas devem estar interligadas, atuando expressivamente no processo de aprendizagem da língua materna. Corroborando os estudos clássicos sobre o peso da origem, se o aluno tem pais analfabetos, a aquisição do seu conhecimento será, invariavelmente, prejudicada. Ou seja, nesse caso, as metodologias de ensino parecem perder autonomia na medida em que estão inteiramente associadas às condições de vida do aluno. Uma sucessão de desencontros é marcada pela distância entre universos linguísticos: a linguagem hermética da universidade não se aproxima da linguagem da escola que, por sua vez, não se comunica com a da família e nem esta com a do aluno. Parece que o poder da escola é menor face às adversidades sociais e, assim, tem mais poder quem domina melhor a língua materna.

Nos grupos de Matemática, os discursos também trataram do hiato entre a teoria e a prática, mas com menor intensidade. Os temas sobre o método predominaram nos debates. Na verdade, ao contrário do grupo de Letramento, aqui nenhuma teoria específica ou nenhum autor em especial foram mencionados. Entretanto, o modo como a disciplina é conduzida na prática foi discutido com bastante ênfase. Os professores acabaram compartilhando experiências de aulas bem sucedidas, denunciando a pouca familiaridade e a baixa frequência com que realizam essas trocas.

Nos grupos mistos e no único grupo formado, exclusivamente, por diretoras, a temática debatida girou em torno do conceito de liderança escolar. A crescente associação entre liderança e qualidade da gestão escolar intensifica a necessidade de aprofundamento do tema. Segundo Lück (2008), a literatura sobre liderança é farta no campo da administração de empresas. Mas somente no final da década de 1970 começam a surgir os primeiros achados sobre liderança no contexto escolar. Para Scheerens (2005), isso se deve ao impacto dos estudos sobre escolas eficazes, nos quais pesquisadores ingleses e norte-americanos 
observaram algo além das já conhecidas associações entre origem social e desempenho estudantil. Ou seja, o fatalismo sociológico da era Coleman começa a ceder espaço para uma nova realidade, que traz para o centro do jogo o potencial do papel da escola.

As percepções sobre o termo liderança revelam uma configuração ainda precária da realidade brasileira no campo da gestão escolar. As pesquisas internacionais apresentam uma gama significativa de resultados sobre o tema há, pelo menos, mais de duas décadas. Vale lembrar que os estudos sobre escolas eficazes, na sua maioria, apontam o efeito da liderança do gestor como um dos principais fatores explicativos dessa equação.

Já nos idos dos anos 1980, Edmonds (1982) coloca, no topo da sua lista das principais características de eficácia escolar, a liderança do diretor e a sua atenção para com a qualidade do ensino. Inúmeros outros estudos fizeram o mesmo ao incluir a liderança como um dos requisitos básicos para o bom desempenho das escolas. É o caso de autores como Levine \& Lezotte (1990); Scheerens \& Bosker (1999); Leithwood, Louis, Anderson \& Wahlstom (2004); Marzano, Waters \& McNulty (2005).

Segundo Valenti (2010), “[...] as pesquisas realizadas pelo movimento das escolas eficazes identificou a liderança instrucional como a característica-chave do sucesso escolar" (Valenti, 2010, p. 50). O mesmo autor fez, na sua tese de doutoramento, um trabalho minucioso de revisão da literatura norte-americana e inglesa acerca do impacto da liderança escolar no desempenho estudantil, ao longo de 30 anos, corroborando seus efeitos positivos.

Em 2004, um grupo de pesquisadores das universidades de Minnesota e Toronto produziu um relatório intitulado "Como a liderança influencia no aprendizado dos alunos". O balanço dessa pesquisa concluiu, entre outros fatores, que "[...] o impacto da liderança tende a ser maior em escolas, onde as necessidades de aprendizagem dos alunos são mais acentuadas" (Leithwood et al., 2004, p. 5, tradução da autora). Achados como esses ganham relevância, particularmente em contextos de desvantagem educacional, tal como o Brasil.

Nesse sentido, o conceito de liderança aqui adotado está essencialmente ligado ao exercício da gestão educacional. Ou melhor, é a liderança escolar propriamente dita, atrelada à ideia de eficácia, que está a ser considerada nesse estudo. Uma liderança centrada no "[...] papel que os líderes desempenham, seus estilos administrativos, a relação deles com a visão, valores e objetivos da escola, e as suas abordagens em relação às mudanças" (Brooke; Soares, 2008, p. 335).

Um sobrevoo nos dados da pesquisa OCGE permite identificar, de forma geral, noções ainda muito preliminares da ideia de liderança. As definições eram, em sua maioria, muito vagas, sem qualquer indício teórico. Nos grupos mistos, a ênfase nas características inatas ficou bastante evidente. As frases curtas e reticentes marcaram os momentos

Educação \& Realidade, Porto Alegre, v. 40, n. 4, p. 1261-1276, out./dez. 2015.1265 
pontuais em que foi solicitado ao grupo algum tipo de caracterização mais precisa da liderança:

Isso aí é uma coisa que se tem ou não se tem (Ana, Grupo Liderança).

O dom da palavra, do convencimento... (Andrea, Grupo Liderança).

Carisma (Cíntia, Grupo Liderança).

A pessoa nasce com isso ou não (Adriana, Grupo Liderança).

Houve, também, resistência em relação ao termo liderança escolar que, muitas vezes, veio acompanhado de forte carga pejorativa. Parecia difícil imaginar um líder sem dissociá-lo de uma prática autoritária, individualista e nociva. Para Vilma, coordenadora pedagógica, a liderança é um negócio complicado. Afinal, Hitler era líder, não é?

Para a maioria dos participantes da pesquisa, a boa liderança escolar deveria estar associada às formas democráticas de gestão: consulta aos grupos, decisões coletivas e trabalho em equipe. Raramente foram apontadas habilidades individuais específicas do líder escolar.Em termosgerais, para osgrupos, essashabilidades nascem com o indivíduo e, dificilmente, podem ser aprendidas. Uns têm mais jeito para a coisa que outros. Ainda assim, é preciso gerir com bastante competência as relações interpessoais mais do que qualquer outro aspecto envolvido na gestão de uma escola. Não basta ter boas intenções, se o grupo não estiver convencido e disposto a colaborar.

A pesquisa identificou o longo caminho a ser percorrido, seja em termos teórico ou prático. Fala-se sobre gestão e liderança ainda de modo muito intuitivo, com base nas atividades rotineiras da escola. Nos grupos mistos, como visto, as definições deixaram a desejar do ponto de vista do rigor e da objetividade. Já o quarto grupo, constituído exclusivamente de diretoras, apresentou uma abordagem mais consistente sobre o termo liderança. Para elas, o gestor deve ser caracterizado pela sua capacidade de ponderação, representação e articulação dos diversos interesses presentes na dinâmica escolar. Além disso, acrescenta Ana, diretora da escola A, a posição de gestor permite vislumbrar o exercício profissional do professor (por já tê-lo sido anteriormente) sob um ângulo privilegiado. Por razões óbvias, o exercício profissional dessas diretoras contribuiu para a construção de conceitos mais objetivos, baseados nas suas experiências diárias.

Em síntese, nos grupos mistos, notou-se certo estranhamento em relação ao termo liderança. Parecia existir, ainda que implicitamente, um tipo qualquer de relação entre liderança e autoritarismo. Os participantes deixavam escapar uma percepção de que o exercício de um líder pode ser carregado de um individualismo exacerbado, em detrimento de formas mais democráticas que requerem um trabalho coletivo. Normalmente, figuras como Nelson Mandela, Gandhi e Jesus Cristo eram apontadas como referências de boa liderança. A resistência ou o estranhamento de se reconhecer uma pessoa tão próxima nos revela uma cultura muito específica de relacionamento no âmbito escolar. $\mathrm{Na}$ 
maioria das falas do grupo de diretoras, constatou-se que o aspecto interpessoal é muito valorizado como capacidade premente ao exercício do bom gestor. Nesse sentido, a liderança é percebida em consonância com a pluralidade dos interesses envolvidos na escola. No grupo das diretoras, as opiniões oscilavam entre a necessidade de se garantir os interesses da instituição e a importância de se obter êxito nas relações interpessoais. Conjugar essas duas esferas - institucional e interpessoal - é uma tarefa complicada, para a qual dedicam muito tempo e energia. Nesse sentido, a liderança está mais associada à capacidade de diálogo e ponderação da gestão com as várias dimensões da escola do que propriamente às iniciativas individuais ou ações centralizadoras.

Os dados aqui apresentados encontram eco em outros estudos. Dentre as raras pesquisas brasileiras de natureza quantitativa sobre liderança escolar, destaca-se o survey, Pesquisa Nacional de Gestão e Liderança $(\mathrm{PNGL})^{3}$, produzido pelo CAEd, em 2009. Gestores de seis estados brasileiros (Ceará, Minas Gerais, Pernambuco, Rio de Janeiro, Rio Grande do Sul e São Paulo) responderam a 128 questões acerca das suas características pessoais e das suas práticas de gestão e liderança. Ao todo, 2477 gestores responderam ao questionário, via web. Quando perguntados sobre os fatores que mais influenciam a sua gestão, os diretores tendem a se dividir entre a dimensão gerencial da sua atividade - cumprir ou fazer cumprir os estatutos e regimentos de sua instituição - e a interpessoal, através da qual buscam consolidar a liderança. Esse achado corrobora, em grande parte, os resultados da pesquisa aqui apresentada, especialmente no que diz respeito à polaridade existente entre gestão institucional e gestão interpessoal.

A PNGL deu origem a alguns trabalhos, tal como o artigo A Gestão Escolar e o Ideb da Escola (Soares et al., 2011). Nele, os autores concluem que algumas características de um diretor eficaz estão altamente relacionadas a quatro das características de liderança propostas por Reynolds \& Teddlie (2008): "Estar próximo à comunidade; procurar apoiar estudantes com dificuldades nos estudos por meio de parceria com pais e professores; conseguir adesão dos professores à gestão, e, por fim, ter atitudes com a intenção de superar obstáculos" (Soares et al., 2011, p.63).

Considerando as especificidades dos temas abordados nos grupos e os aspectos mencionados anteriormente, o desacerto entre teoria e prática apareceu como o grande protagonista dos debates. Esse, sem dúvida, foi o mote dos encontros. Conforme a pesquisa caminhava, a proposição metodológica baseada nos cases adquiriu relevância cada vez maior. Tal como aponta Merseth (1997), há muitas dificuldades de conciliação entre teoria e prática nos métodos tradicionais de ensino. A desarmonia na forma e no ritmo como esses dois elementos são trabalhados e organizados empobrece a partilha do saber. O apelo docente por maior concretude da teoria na prática denota que algo não vai bem e não vai bem há um bom tempo. Essas evidências contribuíram para a elaboração de uma alternativa metodológica que - resumidamente - levasse em

Educação \& Realidade, Porto Alegre, v. 40, n. 4, p. 1261-1276, out./dez. 2015.1267 
conta o learning by doing, a partir dos cases. Para melhor compreender esse novo recurso metodológico, vale um breve registro acerca de sua origem.

Em primeiro lugar, em razão da semelhança entre os temos estudo de caso e método do caso, faz-se necessário pontuar as diferenças existentes entre eles, a fim de evitar qualquer confusão conceitual. O primeiro trata-se de uma metodologia de pesquisa, de natureza qualitativa. Consiste, em termos gerais, numa estratégia para se conduzir uma pesquisa empírica.

Já o case ou o método do caso - como ferramenta pedagógica e referência metodológica adotada na pesquisa aqui apresentada - foi criado por Christopher Columbus Langdell, diretor da escola de Direito de Harvard, no final do século XIX.

A partir de 1871, Langdell deu início a uma série de publicações propondo um tipo de metodologia baseada no pensar empírico/indutivo. Tal proposta invertia a lógica teórico/dedutiva, tradicionalmente utilizada no contexto europeu e, em especial, na Alemanha.

Foi uma revolução na forma do ensino, uma vez que esse método objetivava o estudo prático da lei. Era o estudo da lei viva. A partir da análise dos arrazoados dos juízes, os alunos iam chegando às próprias conclusões sobre a legislação. Não se debruçavam apenas nos compêndios como era o caso do estudo na Alemanha (Menezes, 2009, p. 137).

Langdell foi fortemente influenciado pelos acontecimentos de sua época que imprimiram características específicas no modo de pensar norte-americano. Após a Revolução Industrial e a Guerra de Secessão, o país passou a valorizar a descoberta de experimentos capazes de solucionar os problemas cotidianos. "Dessa forma, tanto as universidades quanto o governo e a própria população só davam atenção ao desenvolvimento das artes práticas" (Menezes, 2009, p. 135). E é com base nesse espírito pragmático que nasce o método do caso, cujo princípio está pautado na ideia de aprender fazendo. Com o tempo, o método sofreu adaptações e, paulatinamente, outras áreas do conhecimento como Administração, Economia, Medicina e Educação passaram a adotá-lo com frequência em seus cursos.

No campo educacional, especificamente, essa apropriação é ainda mais recente e seus efeitos têm sido explorados, em especial, por pesquisadores norte-americanos. Para eles, os cases oferecem uma possibilidade particularmente promissora tanto para a formação de professores e gestores escolares quanto para aqueles que desejam compreender mais profundamente o fenômeno do ensino (Merseth, 1997). Os cases se configuram como um fenômeno relativamente novo nos programas de formação de professores e gestores, nos Estados Unidos (Merseth, 1997). No Brasil, essa metodologia, ainda inédita, pode contribuir significativamente para os programas de formação em educação.

1268 Educação \& Realidade, Porto Alegre, v. 40, n. 4, p. 1261-1276, out./dez. 2015. 
O case methods é uma estratégia que supera algumas das deficiências mais sérias na formação dos profissionais de ensino, principalmente dos gestores educacionais, pois, segundo Shulman (1992), eles são contextuais, locais e situacionais e, por meio da narrativa de uma situação real, comunicam aos gestores que a educação é um domínio complexo que envolve difíceis decisões e julgamentos sutis.

Um case não se faz de narrativas pura e simplesmente: uma boa história, um conto interessante e ponto final. A elaboração de um case exige sustentação teórica consistente para o tratamento dos temas a serem aprofundados. Esse não é o caso de se pensar apenas teoricamente sobre determinada situação, mas na maneira pela qual a reflexão teórica pode contribuir para a resolução de problemas práticos. Exercitar essa habilidade é fundamental para o aprimoramento do processo de tomada de decisão. Por retratarem situações verídicas ou bastante verossímeis, os cases apuram o trabalho analítico ao possibilitar comparações entre os diversos eventos que ocorrem frequentemente no dia a dia da escola.

Nesse contexto, os cases permitem a integração do que se apresenta separado: teoria e prática. Como? Eles são produzidos em função de situações específicas que ocorrem na dinâmica escolar. Desse modo, os seus profissionais, em conjunto, podem discuti-los e mobilizar ideias para depois testá-las no contexto no qual estão inseridos. Esse exercício de reflexão sobre a realidade desenvolve habilidades de análise crítica, resolução de problemas e pensamentos estratégicos.

\section{O Problema nosso de cada Dia}

Como visto anteriormente, a pesquisa OCGE foi concebida com o intuito de produzir alternativas para a melhoria da prática daqueles que atuam na escola. Assim, o desenho de investigação realizado levou em conta dois importantes processos: sistematização de problemas e encaminhamento de soluções. No primeiro deles, foi preciso superar o elemento catártico - tão presente no meio escolar -, a fim de torná-lo um recurso produtivo para futuras intervenções, ou seja, os problemas foram levantados e as queixas foram consideradas, mas de modo sistematizado. O que se fez foi colocar em narrativas (cases) os dilemas mais recorrentes nos grupos. O segundo processo diz respeito às soluções apresentadas aos problemas identificados pelos próprios grupos. Nesse sentido, os cases cumpriram um papel fundamental ao propor questões claras e objetivas sobre que tipo de encaminhamento determinado problema deveria ter. Dois momentos muito distintos, cujos resultados permitiram conhecer mais de perto o contexto de gestão percebido pelos profissionais dessas escolas.

Em cada grupo temático, foram apontados problemas de toda ordem e complexidade, mas, para efeitos didáticos, apresentaremos os mais recorrentes: relação da escola com a família, indisciplina do aluno,

Educação \& Realidade, Porto Alegre, v. 40, n. 4, p. 1261-1276, out./dez. 2015.1269 
desamparo pedagógico, descontinuidades da prática docente e imprecisão no gerenciamento escolar.

De todas as situações problemáticas, a relação da escola com a família sempre ganha destaque. Essa delicada relação atravessa décadas e - entre permanências e rupturas - segue cada dia mais complexa. As incertezas são grandes, mas um dado continua inabalável: quanto mais próximas estiverem essas duas instâncias socializadoras, mais o aluno será capaz de aprender. Essa percepção foi unânime em todos os grupos: professores, coordenadores pedagógicos e gestores corroboram, empiricamente, o que a literatura sobre o tema vem anunciando há tempos.

É possível imaginar algumas situações clássicas para quem vivencia o cotidiano escolar, por exemplo, a baixa frequência de pais em reuniões escolares e um acentuado desinteresse pela escolaridade dos seus filhos, para o caso específico de famílias socialmente desfavorecidas. Em algumas dessas famílias, a situação de total desconhecimento por parte dos pais em relação ao universo escolar pode acentuar ainda mais tais dissonâncias entre um meio e outro. Quantas são as situações em que os códigos escolares estão muito distantes daqueles mobilizados no meio familiar dos alunos?

É o aluno, portanto, o protagonista de uma trama em que diferentes variáveis convivem e, em certo sentido, concorrem entre si, delineando um contexto de situações educacionais favoráveis e/ou desfavoráveis. Ele é o sujeito intermediário que carrega informações, expectativas e valores de um meio para o outro. Se a distância entre essas duas realidades for grande, o aluno acaba, muitas vezes, conduzindo solitariamente a sua própria escolaridade. Na medida em que vai ingressando no mundo escolar, tende a interiorizar normas e códigos específicos de um saber sistematizado.

Quando os valores familiares destoam, significativamente, dos valores escolares, o aluno encontra dificuldades e, dependendo da magnitude dessa distorção, se vê desamparado. Acontece que, ao levar informações que não são simultaneamente valorizadas e/ou compreendidas nessas duas instituições, ele empreende um grande esforço para tentar se adaptar.

A indisciplina, de acordo com os grupos, está absolutamente ligada ao contexto familiar do aluno e inserida, portanto, em uma dimensão extraescolar. É curioso notar a omissão do aspecto pedagógico nesse contexto. Mas em quase todas as falas, essas duas categorias pareciam pertencer ao mesmo campo semântico. É na desordem familiar que os professores costumam buscar explicações para o mau comportamento dos seus alunos. Alegam que alguns aspectos formativos como, por exemplo, saber comer à mesa e tratar os outros com gentileza e respeito, deveriam vir de casa, mas que, de fato, as funções andam confundidas.

A categoria indisciplina nesse caso também agrega situações de desinteresse, violência e apatia do aluno. Tanto gestores como professo-

1270 Educação \& Realidade, Porto Alegre, v. 40, n. 4, p. 1261-1276, out./dez. 2015. 
res e, particularmente, os coordenadores pedagógicos admitem dedicar a maior parte do seu tempo de trabalho para tratar de assuntos disciplinares. Minuto a minuto eles se deparam com algum aluno desinteressado, distraído e bagunceiro, sem contar os dias pesados, em que a violência invade os muros da escola, sem pedir licença.

O problema da indisciplina esbarra em vários campos de ação no interior da escola, sobretudo naqueles em que atua o coordenador pedagógico. Esse polêmico personagem conquistou protagonismo entre os seus colegas de trabalho e, dada à recorrência com que foi mencionado nos grupos, acabou por inspirar a criação de uma nova categoria: o desamparo pedagógico.

O desamparo pedagógico surgiu como a grande surpresa da pesquisa. O sentido dessa expressão começou a tomar corpo e se fez presente na grande maioria dos grupos temáticos. O desamparo revela o fracasso que a função do coordenador pedagógico vem demonstrando em praticamente todas as escolas. Na verdade, ao que parece, essa função está sucateada e não cumpre os objetivos para os quais foi criada. Os professores dizem recorrer aos pares quando precisam tirar dúvidas de conteúdo, pegar dicas e trocar planejamento de aula. Quase nunca recorrem ao coordenador. Nas falas, lamentam não poder contar com esse profissional e com o suporte pedagógico que dele poderia vir. Os professores das séries iniciais manifestam essa necessidade mais declaradamente que os professores das séries finais. De fato, os generalistas reconhecem a dificuldade de lecionar conteúdos específicos, especialmente àqueles relacionados à área de Matemática.

Basicamente, não sobra tempo ao coordenador para elaborar propostas metodológicas centradas nos apelos docentes. $\mathrm{O}$ ritmo acelerado que marca o dia a dia de uma escola acaba por condenar esse profissional ao esquecimento. Ele substitui os professores ausentes, apaga incêndio, controla os alunos indisciplinados e por aí vai. Como está quase sempre indisponível, o professor busca ajuda com o colega da sala ao lado, mesmo porque é mais cômodo. Quando há mais de um coordenador por turno, o trabalho começa a adquirir contornos pedagógicos que rapidamente se fazem notar. A direção da escola também se envolve muito nas questões de indisciplina e, por maior autonomia que tenha comparativamente à coordenação, ambas compartilham do mesmo drama. Por se tratar de uma dimensão essencialmente pedagógica, essa categoria engloba também questões de ordem curricular e metodológica.

O desamparo pedagógico não é resultado exclusivo das lacunas de uma coordenação impotente, mas também representa a carência de orientações práticas voltadas para o trabalho diário realizado com os alunos. Alguns professores chegaram a manifestar um desejo contido de voltar às cartilhas e aos manuais metodológicos. O sentimento de desamparo revela uma insegurança que, em longo prazo, pode comprometer o processo de aprendizagem do aluno. Dominar melhor as meto-

Educação \& Realidade, Porto Alegre, v. 40, n. 4, p. 1261-1276, out./dez. 2015.1271 
dologias de ensino e ter à mão um leque variado de práticas escolares bem sucedidas podem contribuir, efetivamente, para a melhoria do trabalho docente.

A categoria descontinuidades da prática docente envolve múltiplos aspectos que interferem diretamente na aprendizagem do aluno como, por exemplo, a cisão entre o trabalho dos professores dos anos iniciais e finais do Ensino Fundamental. Os grupos constataram o prejuízo sofrido pelos alunos, do ponto de vista do conteúdo e da construção do conhecimento. Esse racha compromete, inclusive, a criação de propostas pedagógicas coletivas e integradas tão importantes para o sucesso no aprendizado do aluno. Além disso, o clima organizacional fica abalado entre os professores, gerando, assim, resultados negativos no funcionamento da escola. Essa categoria também compreende dissonâncias entre teoria e prática, ações coletivas e individuais, instâncias superiores e locais.

A descontinuidade entre as séries é um problema antigo, segundo os professores, e parece só piorar com os anos. Gestão e coordenação buscam caminhos, mas falham na busca de consenso entre os grupos. A construção de um sentido comum que priorize os interesses coletivos e, principalmente, os interesses da instituição não é tarefa fácil. As práticas cotidianas ainda preservam um forte caráter personalista e pouco institucional. As descontinuidades aparecem em quase todas as situações escolares: da escola para a família, no trabalho docente, nos conteúdos, na diversidade discente, nas perspectivas individuais e coletivas, da universidade para a escola, entre outras.

O sentimento de fragmentação está presente no ambiente escolar e compromete a produção de um consenso educacional capaz de conduzir e orientar as práticas escolares, conferindo a elas maior profissionalismo e objetividade. O papel da gestão nesse processo é fundamental.É preciso sedimentar as relações, criar sentidos comuns, fortalecer a cultura escolar, incluir os profissionais, ampliar o diálogo e traçar metas claras. Entretanto, os dados da pesquisa indicam que a gestão precisa estar mais bem aparelhada na condução das suas ações. Os conceitos ainda são muito abstratos e gerais e acabam cedendo espaço à intuição, o que pode ser catastrófico em alguns contextos.

A imprecisão no gerenciamento escolar indica a pouca objetividade com que são desempenhadas as ações do gestor. Os depoimentos registrados nos grupos nos levam a crer que existe algo muito difuso no exercício dessa função. Para muitos, essa é uma competência que vai se desenhando ao longo do mandato e que está muito atrelada aos problemas cotidianos da escola. A imprecisão a que nos referimos abrange componentes de insegurança do gestor e das dificuldades que ele encontra ao administrar conflitos entre grupos e, sobretudo, ao liderar uma escola. A metáfora de apagar incêndios é bastante apropriada para ilustrar essa situação, pois é resolvendo um problema aqui, outro acolá que os gestores passam a tomar alguma consciência sobre o trabalho

1272 Educação \& Realidade, Porto Alegre, v. 40, n. 4, p. 1261-1276, out./dez. 2015. 
que desenvolvem. Os professores participantes da pesquisa, especificamente, defenderam a ideia de que uma boa gestão depende, em grande parte, das características inatas de cada gestor. Já no grupo das diretoras, identificamos uma demanda por conhecimentos mais aprofundados que contribuíssem sobremaneira para a melhoria do ambiente escolar em todas as suas dimensões: pedagógica, administrativa, política e sociocultural.

O aspecto pessoal perpassa fortemente as relações de trabalho na escola e torna o clima, muitas vezes, insustentável para o desenvolvimento de propostas coletivas. Os gestores precisam de instrumentos concretos para aprender a lidar com o gerenciamento de uma escola. É preciso que eles saibam monitorar resultados e se sintam preparados para propor soluções. É possível formar gestores eficazes sim e, para isso, é fundamental que eles conheçam os fatores explicativos dessa eficácia. A tese de que uma boa gestão depende de características inatas é perigosa, jogando à sorte e ao acaso o futuro educacional de uma geração.

As categorias descritas acima sintetizam os problemas mais recorrentes levantados ao longo da pesquisa, orientando, portanto, a elaboração dos cases. Nesse sentido, os problemas ganharam forma narrativa e retornaram às escolas, com a proposta de um novo desafio: imaginar saídas. No que se refere às categorias de problemas, em particular, as resoluções tendiam a eleger modalidades de trabalho coletivo, especialmente nos casos de gestão. Além disso, quase sempre a solução vinha acompanhada da ideia de consenso. Nos grupos temáticos de Letramento e Matemática, os professores propuseram alternativas de planejamento integrado do conteúdo buscando superar, inclusive, a cisão entre as séries iniciais e finais. Quanto às funções da coordenação pedagógica, o encaminhamento sugeriu maior aproximação entre coordenadores e professores com ênfase na resolução de questões práticas. Já as categorias extraescolares, como as famílias dos alunos ou mesmo questões de indisciplina, receberam um tratamento mais pessimista. Cada caso é um caso e as situações problemáticas adquirem um tom mais personalista no interior das escolas. Os gestores se esforçam para estabelecer normas e criar uma dinâmica mais eficiente face aos conflitos externos, mas ainda assim se veem forçados a recorrer a outras instituições, como a polícia, o conselho tutelar, entre outros. Resumidamente, as proposições convergiram para uma tentativa de superar os diferentes níveis de fragmentação aos quais está submetida à escola sem seu cotidiano.

A fase devolutiva identificou muitas lacunas. O roteiro utilizado para a resolução dos cases estabelecia o gerenciamento do tempo para os quatro passos previstos no processo. Essa, sem dúvida, foi a maior dificuldade enfrentada pelos participantes. Em muitos grupos, o tempo se esgotou antes da produção de consenso e a escrita ficou comprometida. Às pressas, muito pouco do que havia sido discutido foi contemplado na exposição das ideias no papel. Normalmente, as propostas foram elabo-

Educação \& Realidade, Porto Alegre, v. 40, n. 4, p. 1261-1276, out./dez. 2015.1273 
radas parcimoniosamente em tópicos, de maneira bastante sucinta. $\mathrm{O}$ debate se estendia em longas intervenções e a pessoa eleita pelo grupo para coordenar as falas se via em apuros.

Os participantes declararam que se viram representados nos cases e que as histórias narradas expressam a realidade que eles vivenciam na escola. Esse foi um dado muito importante, já que a intenção era mobilizar o interesse dos grupos conferindo sentido real as suas motivações. Entretanto, falar dos problemas foi tarefa relativamente fácil para os participantes. Mesmo os mais tímidos não titubearam quando eram solicitados a se pronunciar. Custavam a começar, mas quando engrenavam, os problemas apareciam em cascatas. A falta de familiaridade para encontrar saídas se tornou evidente na fase devolutiva, sobretudo quando era preciso sistematizar o encaminhamento de propostas concretas. Os cases se revelaram uma poderosa ferramenta na organização das problemáticas e no exercício de reflexão sobre a prática. A partir deles foi possível avançar de modo mais produtivo e ordenado nas análises acerca do complexo universo escolar. A pesquisa identificou um campo ainda pouco explorado de grande potencial para a melhoria efetiva de práticas pedagógicas e de gestão: o exercício de sistematizar respostas aos problemas cotidianos.

\section{Considerações Finais}

Em Olhares Cotidianos Sobre a Gestão Escolar, os cases se constituíram em um material rico para a reflexão de práticas existentes dentro da escola. Em termos gerais, eles (sujeitos) contaram as suas histórias. Nós (pesquisadores) ficamos atentos às suas práticas e fizemos delas episódios de uma realidade que se pretende compartilhada. Ao fim e ao cabo, exploramos as percepções desses sujeitos, mas não somente a partir da lógica habitual das investigações qualitativas. Com base nessa metodologia inovadora, verificou-se em que medida os debates, o diálogo, a troca e a partilha - elementos essencialmente democráticos - podem oferecer uma nova perspectiva de ação e intervenção escolar. Como dito anteriormente, essa pesquisa buscou promover situações de reflexão e ação.

Na primeira etapa da pesquisa, na qual os problemas foram levantados, os grupos pareciam em casa, falando de velhos conhecidos. Mas algo mudou. As queixas - tão frequentes no universo escolar - assumiram um tom diferenciado, menos impregnado de senso comum. As colocações não se limitavam ao relato de experiências e ponto final. Havia ali, uma tentativa de se discutir as causas em maior profundidade. Entretanto, antigos hábitos permanecem fortes, como por exemplo, o de transferir responsabilidades. Na década de 1990, Maria Helena de Souza Patto (1999) já anunciava essa prática como uma das razões que justificavam a produção do fracasso escolar. Ao que parece muito pouco mudou nesse aspecto, desde então.

1274 Educação \& Realidade, Porto Alegre, v. 40, n. 4, p. 1261-1276, out./dez. 2015. 
Na fase devolutiva, em que era preciso apresentar soluções aos problemas levantados, os participantes, ao contrário da primeira etapa, não se sentiram mais em casa. Eles se viram representados nos $c a$ ses e quando liam sobre os dilemas demonstravam muito interesse e concentração. Terminavam a leitura empolgados relatando o quanto daquilo tudo fazia parte de suas histórias diárias. No entanto, no momento em que lhes foi exigido coordenar os debates, buscar consenso a partir de um tempo estipulado, as coisas se complicaram. Ficou evidente a dificuldade na organização das ideias e, mais especificamente, na elaboração das resoluções.

Os achados dessa pesquisa apontam para a necessidade de se criar recursos capazes de interferir positivamente nas práticas escolares. É preciso buscar aproximações entre teóricos, professores, gestores, coordenadores, familiares e alunos. O modo como esses personagens apartados conduzem suas trajetórias reflete uma fragmentação generalizada no interior das escolas. Acredita-se, por isso, que pesquisas dessa natureza podem encurtar distâncias conferindo sentido real às práticas cotidianas daqueles que estão envolvidos no cenário educacional brasileiro e internacional.

Recebido em 04 de junho de 2014 Aprovado em 28 de novembro de 2014

\section{Notas}

1 As expressões case ou método do caso são utilizadas no texto com o mesmo sentido.

2 Todos os nomes de pessoas ou escolas que aparecem neste artigo são fictícios.

3 Esse relatório foi publicado internamente pelo CAEd para apresentação no Seminário Internacional de Liderança Educacional e Desenvolvimento Profissional: troca de experiências Brasil-EUA, realizado em 2009.

\section{Referências}

BROOKE, Nigel; SOARES, José Francisco (Org.). Pesquisa em Eficácia Escolar: origem e trajetórias. Belo Horizonte: Editora da UFMG, 2008.

EDMONDS, Ron. Programs of School Improvement: an overview. Educational Leadership, 1982.

LEITHWOOD, Kenneth et al. How Leadership Influences Student Learning. New York: The Wallace Foundation, 2004.

LEVINE, Daniel; LEZOTTE, Lawrence. Unusually Effective Schools: a review and analysis of research and practice. Madison, WI: National Center for Effective Schools Research and Development, 1990.

LÜCK, Heloísa. Liderança em Gestão Escolar. Petrópolis: Vozes, 2008.

MARZANO, Robert J.; WATERS, Timothy; MCNULTY, Brian. School Leadership that Works: from research to results. Aurora, CO: Mid-continent Research for Education and Learning, 2005.

Educação \& Realidade, Porto Alegre, v. 40, n. 4, p. 1261-1276, out./dez. 2015.1275 
MENEZES, Maria Arlinda de Assis. Do Método do Caso ao Case: a trajetória de uma ferramenta pedagógica. Educação e Pesquisa, São Paulo, v. 35, n. 1, p. 129143, jan./abr. 2009.

MERSETH, Katherine. Case Studies in Educational Administration. New York: Longman/Addison Wesley Publisher, 1997.

PATTO, Maria Helena Souza. A Produção do Fracasso Escolar: histórias de submissão e rebeldia. São Paulo: Casa do Psicólogo, 1999.

REYNOLDS, David; TEDDLIE, Charles. The Future Agenda of Studies into the Effectiveness of Schools. In: BOSKER, Roel; CREEMERS, Bert; STRINGFIELDS, Sam (Org.). Enhancing Educational Excellence, Equilty and Efficiency. Dordrecht, 2008. P. 229.

SCHEERENS, Jaap. A Mensuração da Liderança Escolar. Ed. Bilíngue, Brasília: Instituto Nacional de Estudos e Pesquisas Educacionais Anísio Teixeira - INEP, 2005.

SCHEERENS, Jaap; BOSKER, Roel. The Foundations of Educational Effectiveness. International Review of Education, v. 45, n. 1, p. 13-120, 1999.

SHULMAN, Judith H. Case Methods in Teacher Education. New York: Teachers College Press, 1992.

SOARES, Tuffi Machado et al. A Gestão Escolar e o IDEB da Escola. Revista Pesquisa e Debate em Educação, v. 1, n. 1, p. 38-56, jan./jun. 2011.

VALENTI, Michael. Leadership Responsibilities Associated with Student Academic Achievement: a study of the perspectives of national distinguished elementary school principals in an era of high stakes accountability. 2010. 180f. Thesis (Doctor of Education) - Seton Hall University, New Jersey, 2010.

Fabiana Martins Coelho é graduada em Pedagogia pela Universidade Federal de Juiz de Fora (1999), mestrado em Educação pela Universidade Federal de Juiz de Fora (2001) e doutorado em Sociologia pelo Instituto Universitário de Pesquisas do Rio de Janeiro (2007). Atualmente é professora colaboradora do Programa de Mestrado Profissional em Gestão e Avaliação da Educação Pública e coordenadora de Projetos de Pesquisas CAEd/UFJF. E-mail: bia@caed.ufjf.br 